\title{
LA DEFENSA DE LA REPÚBLICA Y LOS DERECHOS A LA RENTA DEL SUELO Y A LA EXISTENCIA EN THOMAS PAINE Y MAXIMILIEN ROBESPIERRE. ANÁLISIS COMPARATIVO
}

\author{
THE DEFENSE OF THE REPUBLIC AND THE RIGHTS \\ TO THE INCOME OF THE SOIL AND THE EXISTENCE \\ IN THOMAS PAINE AND MAXIMILIEN ROBESPIERRE. \\ COMPARATIVE ANALYSIS
}

María LuISA SORIANO GONZÁLEZ
Universidad Pablo de Olavide

Fecha de recepción: 27-1-19

Fecha de aceptación: 17-12-19

Resumen: El trabajo es un análisis comparativo de dos cuestiones presentes en los escritos de Tomas Paine y Maximilen Robespierre: la defensa de la república y el reconocimiento de los derechos sociales. Ambos defienden una república representativa, pero difieren en el proceso de construcción y en el uso de la violencia. Ambos persiguen la supresión de la pobreza, pero el derecho a una renta del suelo de Paine es universal e incondicionado, mientras que el derecho a la existencia de Robespierre no atañe a todas las personas, sino a las que son pobres o carecen de trabajo. Consecuentemente, Paine puede ser considerado el precursor de la renta básica universal y Robespierre un pionero defensor del derecho de subsistencia condicionado.

Abstract: The work is a comparative analysis on two issues present in the writings of Tomas Paine and Maximilen Robespierre: the defense of the Republic and the recognition of the social rights. Both defend a representative republic but differ in the process of construction and the use of violence. Both also pursue the suppression of poverty, but the right to income of Paine is universal and unconditional while the right to the existence of Robespierre does not refer to all persons but those who are poor and lack of work. As a result, Paine can be considered the forerunner of universal basic income and Robespierre a pioneering advocate of the conditional subsistence right.

ISSN: 1133-0937

DERECHOS Y LIBERTADES

DOI: https://doi.org/10.20318/dyl.2022.6516

Número 46, Época II, enero 2022, pp. 115-144 
Palabras clave: derecho a la existencia, república, renta básica universal Keywords:

right to existence, republic, universal basic income

\section{INTRODUCCIÓN}

El objetivo de este trabajo es precisar los nexos y divergencias entre Paine y Robespierre en dos cuestiones: a) cuál es la diferencia en la definición y alcance de la libertad de la república, y b) en qué medida pueden ser considerados ambos pioneros o precursores de la renta básica universal y cuál es la diferencia entre ellos en relación con esta renta, si es que existe. ${ }^{1} \mathrm{La}$ segunda cuestión necesita una previa aclaración en sede definitoria, motivo por el que dedicaré un primer epígrafe a definir brevemente en qué consiste la renta básica universal.

Sobre las libertades en ambos autores hay una copiosa bibliografía, después de un periodo largo en el que los dos fueron considerados autores malditos y no eran citados sino para despreciarles. ${ }^{2}$ Pero mucho menor es la bibliografía sobre el análisis comparativo de ambos en lo que denominaban según la literatura de la época derecho a una renta del suelo y derecho a la existencia (semejantes a lo que hoy denominamos renta básica universal). Es oportuno, consecuentemente, precisar el significado y el alcance de la renta básica universal, tal como hoy la considera la doctrina, para a continuación justificar hasta qué punto los revolucionarios del siglo XVIII, Paine y Robespierre, pueden ser considerados pioneros de la misma, ya que en una extensa literatura se otorga a ambos el título de pioneros de una renta básica universal. $^{3}$

\footnotetext{
1 En adelante sustituiré la mención a la renta básica universal por sus siglas: RBU.

2 Véase sobre la historia negra de Robespierre la monografía de J. R. RALLO, Contra la renta básica, Deusto, Bilbao, 2015.

3 Basta leer las obras generales insertas en la web de la Red Renta Básica Española, para advertir la frecuencia con la que Paine y Robespierre son citados expresamente como precursores o pioneros de la renta básica universal. Para un conocimiento de la historia doctrinal de esta renta recomiendo la obra de J. IGLESIAS, Las culturas de las rentas básicas. Historia de un concepto, Virus editorial, Barcelona, 2004, que presenta el interés de contener textos acotados de los autores en edición bilingüe. Asimismo las obras de un académico experto en la materia, D. Cassasas, autor de una prolífica literatura sobre la RBU, de la que destaco su última obra, Libertad incondicional. La renta básica en la revolución democrática, Paidós Ibérica, Barcelona, 2018. Igualmente, para tener una primera visión del significado y problemática de esta renta es conveniente la lectura de una obra de Cive Pérez, periodista y activista social, titulada Renta básica universal, Clave intelectual, Madrid, 2015. Hay que destacar también la
}

DERECHOS Y LIBERTADES

Número 46, Época II, enero 2022, pp. 115-144
ISSN: $1133-0937$

DOI: https://doi.org/10.20318/dyl.2022.6516 
En la cuantiosa literatura sobre ambos autores y su relación con la RBU apenas se le dedica una pasajera atención, indicando sin más algunas frases de sus obras, y desde luego no existe, hasta donde llega mis noticias, una clara distinción entre ellos en la definición y los argumentos favorables a la RBU. Por lo tanto, una aportación de este trabajo consiste en una investigación no realizada: la comparación de Robespierre y Paine en el tema concreto de la RBU. Por descontado que hay trabajos que comparan ambas figuras, pero no dedicados al examen comparativo en la cuestión concreta apuntada. Conocía los escritos de ambos autores y entreveía que no eran susceptibles de colocarles en el mismo plano, y que quizás los derechos que ellos defendían no eran asimilables a lo que hoy entendemos como renta básica universal. La otra aportación es la de precisar las diferencias en el concepto de república.

Paso a continuación a indicar las notas más importantes sobre la RBU. Mi definición de la renta básica universal en un trabajo anterior sobre el derecho de subsistencia en Luigi Ferrajoli y su equiparación con la renta básica universal era la siguiente: "La renta básica en pocas palabras es el derecho individual e incondicionado a recibir una prestación del Estado para atender a las necesidades básicas". ${ }^{4}$ La definición más simple es la de los profesores Daniel Raventós, presidente de la Red Renta Básica en España, y de Ramón Soriano expresada en la presentación de un debate sobre la renta básica: "La renta básica es una asignación monetaria incondicional para toda la ciudadanía y residentes acreditados" ${ }^{5}$ Ramón Soriano, por su parte, amplía la definición de esta manera: "un ingreso mínimo incondicionado para los ciudadanos y residentes de pleno derecho, compatible con otros ingresos, que tiene la finalidad de garantizar su derecho a la subsistencia y su libertad real, satisfaciendo sus necesidades más

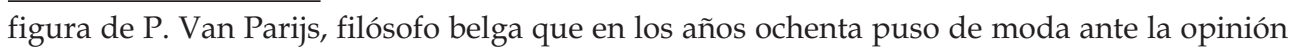
pública la RBU por medio de una atrevida publicación, en la que defendía que la RBU era un medio para alcanzar el comunismo desde el capitalismo. El artículo "Una vía capitalista al comunismo", redactado por Van Parijs y Van der Beer, fue publicado en la revista Theory and Society (núm. 15, 1986), y puede ser consultado en la revista Zona Abierta, 1988, pp. 19-45.

$4 \quad$ M. L. SORIANO GONZÁLEZ, "La renta básica y el derecho de subsistencia en Luigi Ferrajoli", Cuadernos Electrónicos de Filosofía del Derecho, núm. 26, diciembre de 2012, p. 232.

5 D. RAVENTÓS, R., SORIANO, “A modo de presentación. La renta básica: ¿una propuesta justa, razonable y posible?", Revista Internacional de Pensamiento Político, núm. 5, 2010, p. 190. Es la introducción de ambos autores al interesante "Debate de RIPP" sobre la renta básica, en el que participaron los expertos en el tema como Arcarons, Lo Vuolo, Rey, Yanes y Zubero. 
elementales". ${ }^{6}$ Una definición más amplia y autorizada es la de la asociación Basic Income Earth Network (BIEN): "ingreso incondicionado pagado a todos individualmente, sin sujetarlo a ningún test de recursos o al requisito de trabajar". Lo importante en la definición es precisar que se trata de un derecho incondicionado y que, por lo tanto, no exige una condición o situación determinadas del beneficiario/a de la renta -estar en paro, escasa retribución, enfermedad o incapacidad, etc.- para recibir la prestación del Estado. La persona o el ciudadano es titular de la renta de la misma manera que lo es de las libertades: por ser persona o ciudadano del Estado.

En el citado trabajo de Raventós y Soriano se señalan los caracteres de esta renta: a) individual (no se concede únicamente a la familia u hogar familiar como es frecuente en los subsidios), b) incondicional, cualidad que la separa de los subsidios sociales que exigen demostrar algunas carencias materiales o una actitud activa del subsidiado ante el trabajo, c) universal, pues todos los ciudadanos y residentes estables pueden acceder a ella, d) básica, porque se trata de un ingreso modesto a partir del cual pueden sumarse otras rentas provenientes de distintas fuentes, e) periódica (mensual o anual como periodicidad habitual), f) en efectivo (en especie tendría el problema de restringir las posibilidades que ofrece el dinero efectivo), g) compatible con otras rentas como los salarios del trabajo, h) independiente de estatus y nivel de renta, situación ante el trabajo, etc., de la persona, i) estatal, aunque nada impide que una institución jurídico-política por encima del Estado (la Unión Europea, p. e.) o por debajo (una comunidad autónoma, p.e.) otorgue una renta básica a los ciudadanos pertenecientes a un determinado territorio. ${ }^{7}$

Hoy presenta la RBU dos temas nada pacíficos; uno es el de su cualificación jurídica, que entra de lleno en la controvertida cuestión de las vías para su reconocimiento jurídico, recibiendo de la doctrina la catalogación como derecho social o garantía de derecho o libertad pública. El segundo se refiere a la relación de la RBU con las teorías filosófico-jurídicas clásicas: el liberalismo, el socialismo y el republicanismo. Es obvio que el segundo tema interesa especialmente a la filosofía jurídica.

La relación de la RBU con los derechos sociales es muy acentuada y compartida, porque cuando la doctrina se plantea las vías de reconocimiento

6 SORIANO, R., Por una renta básica universal. Un mínimo para todos, Almuzara, Córdoba, 2012, p. 19.

D. RAVENTÓS, R. SORIANO, “A modo de presentación. La renta básica: ¿una propuesta justa, razonable y posible?”, cit., pp. 193-194. 
jurídico de esta renta señala que el camino más adecuado es considerarla como un derecho social, de tal modo que vendría a representar el último derecho social conquistado e incorporado al ordenamiento jurídico de los países avanzados o el derecho social-compendio de los otros derechos sociales. Las otras vías menos solventes de reconocimiento serían la de contemplarla como una garantía de un derecho o una modalidad de libertad. Y así es un derecho social para L. Ferrajoli ${ }^{8}$, una modalidad de libertad, la libertad real, para P van Parijs ${ }^{9}$ y una garantía del derecho al trabajo para José Luis Rey ${ }^{10}$.

Respecto a la concepción de la RBU en el marco de las teorías clásicas de la filosofía jurídico-política las posiciones son diversas, y en todas ellas podemos encontrar aspectos que las unen y otros que las separan de esta modalidad de renta. La RBU se relaciona con claroscuros con el liberalismo, porque responde bien al postulado liberal de la autonomía de la persona y mal a otro postulado, el concepto de Estado abstencionista. La RBU permite el programa individual de vida de la persona porque le concede la independencia que supone un mínimo vital para atender a sus necesidades. Por otro lado, esta renta casa mal con la exigencia de la abstención estatal, con la no cooperación del Estado ayudando a las personas en situación de precariedad y redistribuyendo la riqueza. El Estado liberal es un modelo estatal que se mantiene al margen de las relaciones jurídicas privadas, y sin embargo la RBU comporta la idea de un Estado prestacionista.

La RBU se relaciona con el socialismo, porque es el medio para conseguir sus postulados, como es la libertad real, ya que el socialismo ha criticado, tanto el radical y antiestatalista como el moderado y estatalista, el concepto de libertad del liberalismo, porque es una libertad formal, retórica e ineficaz, que no es posible sin su sustitución por una libertad real, aquélla que únicamente pueden disfrutar quienes disponen de unas condiciones socioeconómicas adecuadas para el disfrute de sus derechos. La RBU es el medio para hacer posible esa libertad real. Esta renta sería el primer paso para llegar a una sociedad socialista sin clases sociales; un instrumento para alcanzar un fin. Por otro lado, el socialismo, sobre todo el socialismo clásico,

8 L. FERRAJOLI, Derechos y Garantías. La ley del más débil, Trotta, Madrid, 2001 y Principia Iuris. Teoria del diritto e della democrazia. 2. Teoria della democrazia, Laterza, Roma-Bari, 2007.

9 P. VAN PARIJS, Libertad para todos. ¿Qué puede justificar al capitalismo (si hay algo que puede hacerlo)?, Paidós, Barcelona, 2006.

10 J.L. REY PÉREZ, El derecho al trabajo y el ingreso básico ¿Cómo garantizar el derecho al trabajo?, Dykinson, Madrid, 2007. Una síntesis en Revista Internacional de Pensamiento Político, núm. 5, 2010, p. 205. 
ha considerado al trabajo como el derecho universal a conquistar, y por ello es renuente con este propósito una renta que se pretende incondicionada y no sujeta a ninguna circunstancia y contraprestación (entre ellas precisamente el trabajo).

La renta básica universal se relaciona con el republicanismo, porque hace posible sus postulados más importantes: la participación política ciudadana, la virtud del ciudadano, los deberes cívicos del ciudadano. Una RBU haría a las personas ciudadanos virtuosos y participativos, que cumplirían con sus deberes cívicos, ya que dispondrían del mínimo vital para participar en la política de su país y convertirse en ciudadanos activos. Por otro lado, es evidente que uno de los principios del republicanismo, el cumplimiento de deberes cívicos, exige del ciudadano una actitud activa y responsable, que no se compadece bien con una renta que se concede a la persona por su propia condición de persona, sin exigirle a cambio una contraprestación.

Pasamos ahora al análisis del objeto de este trabajo: las diferencias entre el inglés Paine y el francés Robespierre en el concepto de república y del derecho a una renta del Estado, que en el primero recibía el nombre de derecho a la renta del suelo y en el segundo derecho a la existencia (a la subsistencia, diríamos en el lenguaje de nuestra época).

\section{THOMAS PAINE}

Thomas Paine es el hombre de las dos revoluciones liberales del siglo XVIII. Primero la revolución de América y después la revolución de Europa. Teórico y práctico de ambas revoluciones, se convirtió en una de las personalidades más influyentes en su tiempo. Al igual que Jefferson, coetáneo y republicano como él, llevó una vida intensa repartida entre la reflexión y la escritura y el activismo político. ${ }^{11}$ También aplicó una misma visión y fundamentos a los cuantiosos temas que trató en sus escritos: independencia de las colonias, formas de gobierno, abolición de la esclavitud, derechos de los

11 Lloyd S. Kramer tras señalar las grandes diferencias entre Jefferson y Paine en sus vidas -la vida cómoda y de reconocimiento social del primero y la vida llena de obstáculos y peligros acompañada del desprecio social debido a sus ideas religiosas del segundo- a continuación subraya la cualidad que une a ambos: la unión de la reflexión teórica y la actividad política: "Paine y Jefferson sobresalen en la historia de la teoría política como figuras que combinaron sus escritos con frecuente participación en la lucha por el poder político" (L.S. KRAMER, Paine and Jefferson on Liberty, Continuum, Nueva York, 2000, p. 8).

DERECHOS Y LIBERTADES

ISSN: $1133-0937$

Número 46, Época II, enero 2022, pp. 115-144

DOI: https://doi.org/10.20318/dyl.2022.6516 
ciudadanos, derechos de las mujeres, derechos de los animales, etc. Enfocó todo desde los nuevos valores liberales y un nuevo iusnaturalismo basado en la razón humana. Fue agasajado con el título de diputado de honor de la Convención francesa y la nacionalidad honorífica francesa. Dos hechos le llevaron a la fama entre sus coetáneos: su obra El Sentido Común, de 1776, en la que defendía la conveniencia de la separación de las colonias británicas de América septentrional de la metrópoli Inglaterra, y posteriormente su polémica con el conservador inglés Edmund Burke, quien frente al racionalismo jurídico de Paine y sus derechos naturales oponía la tradición jurídica y los derechos históricos. Burke había publicado un extenso libro, Reflexiones sobre la Revolución francesa, en 1790, y Paine le respondió en el corto plazo con otro extenso libro, Los Derechos del Hombre, redactado en los años 1791-92. Ambas obras son cruciales para entender, respectivamente, sus razones para la independencia de las colonias y su construcción de una república como forma de gobierno.

El parecido de Paine con Robespierre es enorme. Ambos pertenecen al ala radical de las revoluciones americana y europea; ambos también se caracterizan por la defensa de la república, la libertad religiosa, la igualdad en el disfrute de los derechos políticos y la supresión de la pobreza. El parecido es tan grande que ambos también sufrieron el olvido y desprecio de generaciones posteriores hasta que finalmente han sido rehabilitados y hoy son considerados como relevantes artífices de las revoluciones de la segunda mitad del siglo XVIII, dotados de un discurso político propio y radical. Paine además es agasajado en Estados Unidos como uno de los Padres Fundadores.

Pero, en contraste con ambos, Jefferson y Robespierre, Paine supo empatizar con el público en general, porque a la pasión en la exposición de sus ideas (en lo que se asemejaba a Robespierre y se apartaba de Jefferson), supo añadir un verbo directo y popular, para que sus palabras alcanzaran al mayor número de personas. ${ }^{12}$ Por lo demás la vida de Paine estuvo salpicada de circunstancias contradictorias. La mayor de ella es que tras su enorme fama, y pudiendo atesorar una fortuna, murió pobre, solitario y olvidado en Nueva York. ${ }^{13}$

12 M. Butler destaca el "uso del vocabulario y ritmos populares" por Paine (M. BUTLER, Burke, Paine, Godwin and the Revolution Controversy, Cambridge University Press, Cambridge, 1984, p. 17).

13 Cito algunas contradicciones de su biografía. Fue perseguido y condenado en rebeldía por alta traición en Inglaterra por el Gobierno inglés por sus escritos contra la monarquía y estuvo a punto en Francia de ser condenado a muerte por oponerse a la pena de muerte del 


\subsection{El derecho al propio gobierno y la defensa de la república}

Voy a tratar la defensa de la república sostenida por Paine con las miras puestas en Robespierre, pues no es objetivo de estas líneas explicar el concepto de república del autor, sino las similitudes y diferencias con Robespierre. Lógico es que la comparación exige previamente examinar el concepto de república de ambos pensadores y actores políticos.

En el conjunto de los autores liberales del siglo XVIII Paine se significa por la innovación en varias libertades: a la autodeterminación política, a la libertad religiosa y al voto. Su posición cerrada en favor de estas libertades le granjeó la enemistad de los conservadores de la época, viéndose envuelto en varias polémicas. Defiende la independencia de las colonias de la América septentrional respecto a Inglaterra, la defensa de lo que Paine llamaba el "derecho al propio gobierno" (que es el título que le da a este nuevo derecho y que nosotros enunciaríamos como derecho a la autodeterminación de los pueblos) con lo que pretende que las colonias británicas se separen de Gran Bretaña y adquieran su independencia instaurando un nuevo modelo de gobierno, la república.

El derecho al propio gobierno se sustenta en dos argumentos, uno estratégico y otro racionalista. ${ }^{14} \mathrm{El}$ primero consiste en un cálculo de ventajas e inconvenientes, expuesto en su libro antes citado, El sentido común, donde llega

rey francés Luis XVI, exigida en la Convención precisamente por Robespierre. En el mismo periodo de tiempo Robespierre pronunció su discurso contra el ateísmo y a favor de la religión de Estado en la Convención francesa, mientras Paine, encarcelado, escribía La Edad de la Razón, defendiendo la libertad religiosa. Recibió una fortuna como derechos de autor de sus libros, bestsellers en su época, muy reeditados, que regaló a instituciones y asociaciones que luchaban por la independencia de las colonias inglesas y la promoción de los derechos humanos, viviendo y muriendo pobre. Los comentarios de sus coetáneos muestran que fue un hombre de extraordinario espíritu generoso, desprendido, y que supo perdonar a quienes le injuriaban. Como afirma F. Santos en su introducción a Los derechos del hombre (Alianza Editorial, Madrid, 1984, p. 21) "algunos estudiosos han llegado a calcular que solo en 1792 y 1793 se vendieron más de un millón de ejemplares", cuyas ganancias Paine entregó al tesoro de la guerra de la independencia y a instituciones progresistas. B. Altamirano en otra introducción del mismo libro (Los derechos del hombre, FCE, México, 2017, p, 9) y en la misma línea de los contrastes recuerda que en América fue prestigioso cofundador de una república y posteriormente sus compatriotas le olvidaron y que en Francia le concedieron la nacionalidad honorífica y después le encarcelaron en la era del terror.

14 Así como el primer argumento está presente extensamente en la obra citada, El Sentido común, con algunas breves referencias en obras posteriores, el segundo hace acto de presencia en esta obra también extensamente, pero se despliega después de una manera amplia en las obras posteriores del autor, especialmente en Los derechos del hombre, y forma parte 
a retar a que cualquiera demuestre una sola ventaja derivada de la anexión de las colonias a Gran Bretaña. El segundo se apoya en un derecho natural dentro de la lista de los nuevos derechos naturales de libertad productos de la razón y en un derecho generacional, el derecho de una generación a establecer libremente una línea de gobierno con independencia de sus antepasados, pues como Paine reitera en sus escritos y en su polémica contra Burke los muertos no tienen derechos contra los vivos. ${ }^{15}$

El argumento estratégico ocupa el mayor número de páginas de El sentido común, en la defensa de la independencia y la creación de un gobierno propio por las colonias británicas. Las razones son varias. No interesa a las colonias verse involucradas en las guerras continuas de Inglaterra con los Estados europeos; guerras continuas que en nada beneficia a las colonias y que tendrán que ser sufragadas por ella. Igualmente la dependencia de las colonias de las relaciones comerciales de Inglaterra, cuando les interesa el libre comercio sin ataduras, sobre todo porque disponen de excelentes recursos naturales; pone el ejemplo del comercio del trigo, que sufre las cortapisas de los aranceles e imposiciones del gobierno británico. Otro inconveniente es la larga distancia de las colonias respecto a Inglaterra. Y una razón de peso, porque conecta con el motivo originario de la fundación de las colonias, es la libertad religiosa, de creencias y culto, que obligó a gran parte de los británicos a exilarse y buscar en América una libertad para la práctica de su religión que la monarquía inglesa les negaba. ${ }^{16} \mathrm{Y}$ no podía faltar el alegato contra un monarca absoluto, el rey inglés, quien además de gobernar sin control, ejercería el derecho de veto contra las decisiones tomadas en el Continente (expresión frecuente en Paine

de una obra breve y tardía que contiene un resumen de sus principios, La disertación sobre los primeros principios del gobierno, de 1795.

15 En un párrafo cita al propio Burke como guardián de los muertos que impiden a los vivos actuar con libertad: "el Sr. Burke propugna la autoridad de los muertos sobre los derechos y la libertad de los vivos" (T. PAINE, Los derechos del hombre, Alianza Editorial, Madrid, 1984, p. 37). Véase el contraste entre Burke y Paine en relación con la justificación de la forma de gobierno en el libro reciente de Y. LEVIN, El gran debate. Edmund Burke, Thomas Paine y el nacimiento de la derecha y de la izquierda, Gota, Madrid, 2015, pp. 271-300, en el que considera a ambos los fundadores de los partidos conservadores y liberales. El debate continuó y sigue en la actualidad según R.B. DISHMAN (Burke and Paine, Charles Scribner's Son, Nueva York, 1971, p. 67), quien termina su monografía afirmando "El debate quedó inconcluso en su tiempo y continúa inconcluso en el nuestro".

16 Con ironía afirma Paine advirtiendo que el descubrimiento de las nuevas tierras precedió a la Reforma "como si el Todopoderoso hubiera querido abrir un santuario a los perseguidos en el futuro, cuando la patria no depara ya amistad ni seguridad". (R. SORIANO, E., BOCARDO, El sentido común y otros escritos, Tecnos, Madrid, 1990, p. 31).

ISSN: 1133-0937

DOI: https://doi.org/10.20318/dyl.2022.6516
DERECHOS Y LIBERTADES

Número 46, Época II, enero 2022, pp. 115-144 
para referirse al territorio de las trece colonias inglesas), y que serían sometidas a los intereses prioritarios de las guerras y relaciones de Inglaterra con los Estados europeos. "No se harán otras leyes -concluye Paine- que las que el rey deje hacer". Y la situación de inestabilidad en el ínterin de que las colonias alcancen la inevitable independencia, provocando que nuevos emigrantes dejen de venir por temor y muchos residentes por la misma razón abandonen el territorio de las colonias. Finalmente una razón de primera fila: la conveniencia de que las colonias constituyan Estados libres para que las demás potencias las traten como a un igual; mientras no sea así, no contarán en el concierto de las naciones, que siempre las verán como un apéndice político y territorial de Inglaterra. Paine sigue desbrozando otras razones de menor peso para la independencia, que cito brevemente, por no permitirlo la extensión de este trabajo: las monarquías siempre están en guerra entre ellas, la falta de confianza en la protección de Inglaterra en caso de necesidad, como ya se ha demostrado, la libre extracción y comercialización de recursos, sin trabas, de los que carece Inglaterra, la existencia de tierras vírgenes que serían concedidas a dignatarios de la Corona, la juventud de las colonias, que les proporciona entusiasmo y fuerzas, la ausencia de mediación de otras potencias en tanto las colonias sean súbditas de Inglaterra.

El argumento racionalista entra de lleno en los derechos naturales de libertad defendidos por Paine, entre los que señala el derecho al gobierno propio: "Tener un gobierno propio -afirma taxativamente- es nuestro derecho natural" ${ }^{17} \mathrm{Y}$ este auto-gobierno implica el derecho a la creación de una Constitución propia. Pero este derecho natural se queda en el gobierno de una nación, y no tiene consecuencias hacia generaciones futuras. Cada generación tiene derecho a establecer su propio gobierno, de la misma manera que también lo tienen las generaciones que le sucedan. Una generación no puede implicar a las futuras. En este argumento Paine rompe la línea de continuidad que predicaba Burke, exigiendo que los derechos y obligaciones, que denominaba de carácter histórico, estipulados por la tradición vincularan a la sucesión de generaciones futuras. Son numerosos los párrafos de las obras de Paine defendiendo que una generación es libre de establecer su gobierno. Elijo uno ilustrativo y contundente: "Cada edad y cada generación deben tener tanta libertad para actuar por sí mismas en todos los casos (cursiva del autor) como las edades y las generaciones que las precedieron" ${ }^{18}$

17 SORIANO, R., BOCARDO, E., El sentido común y otros escritos, cit., p. 42.

18 T. PAINE, Los derechos del hombre, cit., p. 36. 
Paine ha defendido hasta ahora el derecho al gobierno propio, pero ¿qué tipo de gobierno cree más conveniente para los nuevos Estados independientes? ${ }^{19}$ En este segundo escenario el pensador y activista inglés despliega su concepción de un nuevo Estado ideal, al que denomina república, tras el examen de las formas de gobiernos históricas. Opone república a monarquía, para la que tiene los peores dicterios, suprimiendo la fórmula tradicional de los gobiernos buenos y malos de Aristóteles, y considera que la mejor república es la representativa. Distingue simplemente dos tipos de gobierno: "El gobierno por elección y representación y el gobierno por sucesión hereditaria. Al primero se le conoce generalmente por el nombre de república; al segundo, por el nombre de monarquía o aristocracia" ${ }^{20}$

La república es obra del contrato social ("concierto mutuo" es su expresión) de los hombres, quienes eligen a sus representantes y gobernantes. Los hombres constituyen la nación de la que emana la soberanía y la nación tiene el "derecho inherente e inderogable" de crear una forma de gobierno y abolirla después, si es su voluntad, para crear otra en su lugar. ${ }^{21}$ En la república los derechos naturales de la persona, que todos poseen porque por naturaleza son iguales, se convierten en derechos civiles. Paine es copartícipe en el dibujo de la república con la mayoría de los liberales de las colonias inglesas y de Francia. Se diferencia de ellos en la plena igualdad del derecho al voto (en lo que concide, como veremos, con Robespierre) y en la también plena libertad religiosa como libertad de conciencia (en lo que se separa de él). Respecto al voto advierte: "Desde cualquier lado del caso, es peligroso e imprudente, a veces ridículo y siempre injusto, hacer de la propiedad el criterio del derecho al voto". ${ }^{22} \mathrm{Y}$ respecto a la religión: "Debe ser un indispensable deber de todo gobierno proteger la libertad de conciencia....Es voluntad del Todopoderoso que tenga que haber una diversidad de opiniones religiosas

19 Aunque Paine reitera sus temas y argumentos en la mayoría de sus obras, es en Los derechos del hombre donde dedica una mayor atención a las formas de gobierno, contrastando la república con la monarquía, y defendiendo con sólidos argumentos a aquélla contra ésta, e incluso entrando en detalles sobre la organización de la república con acentos modernos (hay Estados democráticos que no observan algunos requisitos que él exigía más de dos siglos antes.

20 T. PAINE, Los derechos del hombre, cit., p. 142.

21 Es claro que en estos momentos dulces revolucionarios, en los que en América y Europa caían los monarcas absolutos y eran sustituidos por repúblicas parlamentarias, a Paine no se le ocurría que los hombres soberanos pudieran querer construir otra forma de gobierno que no fuera la república.

22 R. SORIANO, E. BOCARDO, El sentido común y otros escritos, cit., p. 84.

ISSN: 1133-0937

DOI: https://doi.org/10.20318/dyl.2022.6516
DERECHOS Y LIBERTADES

Número 46, Época II, enero 2022, pp. 115-144 
entre nosotros" ${ }^{23}$ Paine defiende la libertad religiosa frente al cristianismo fanático e intransigente, llegando en la segunda y tercera parte de su libro La Edad de la Razón a describir las contradicciones de la Biblia, los textos desvirtuados, la imposibilidad de los milagros, lo que le granjeó la enemiga de muchos coetáneos y el olvido y desprecio de las generaciones futuras corriendo la misma suerte que Robespierre. Salvaba de sus dicterios a los cuáqueros, "la única confesión que no llevó a cabo persecuciones por razón de religión". Como afirma H. H. Clark: "Paine citaba a los cuáqueros como la única excepción a la crueldad de las confesiones cristianas". ${ }^{24}$

\subsection{La redistribución de la riqueza y el derecho universal a una ren- ta del suelo}

Los estudiosos de la RBU suelen indicar que son pioneros de la misma Robespierre y Paine. Podemos aceptar este papel de pioneros, pero ambos no tienen el mismo significado; no es cuestión de opinión sino de afirmación avalada por los hechos. Robespierre plantea una renta para los casos en que una persona no trabaje o esté en la pobreza. Paine para todas las personas con independencia de si trabaja o no y de cualquier otra circunstancia. Robespierre habla del derecho a la existencia. Paine del derecho a la renta del suelo.

Antes de entrar en la consideración de la renta del suelo hay que precisar cierta contradicción en la figura de Paine, que no deja de ser un hombre de su tiempo. Vamos a demostrar que es el autor de un verdadero proyecto de renta básica universal: que todas las personas reciban una prestación económica del Estado por el mero hecho de serlo, de una manera incondicional. Es una idea muy avanzada, que entraña nada menos que la supresión de la pobreza a medio plazo y la extensión a todos de la propiedad. Sin embargo, no es el autor más radical en el diseño de un nuevo proyecto económico, pues se mantiene en un punto medio entre los partidarios de la supresión de la propiedad privada y los que meramente pretendían una reforma económica basada en la imposición de impuestos a los ricos terratenientes. Un punto medio entre igualitaristas y meros reformistas. ${ }^{25}$ Uno de sus biógrafos, H.J.

23 R. SORIANO, E. BOCARDO, El sentido común y otros escritos, cit., pp. 53-54.

24 H.H. CLARK, Thomas Paine, Hill and Wang, Nueva York, 1961, p. 13.

25 Una posición equidistante entre los radicales franceses que pretendían sustituir la propiedad privada por el colectivismo de la comunidad de bienes -Babeuf, Morelly, Mably- y los fisiócratas, defensores de la libertad económica libre de trabas y de una imposición sobre 
Kaye, le llama "el más grande radical de una época radical" ${ }^{26}$ Pero creo que es necesario matizar, porque Paine fue un radical en la defensa de los derechos civiles, pero no fue abolicionista de la propiedad privada y partidario de la propiedad comunal y el colectivismo económico.

Tanta importancia tiene en Paine una renta básica para todas las personas que le dedicó un libro, Agrarian Justice, Justicia Agraria, formando parte de la exigua lista de autores del siglo XVIII, que fueron más allá de las libertades y promovieron los derechos sociales. Para el autor inglés la igualdad en el disfrute de las libertades iba unida al goce de unas condiciones de vida mínimas y la cubertura de las necesidades básicas. Justicia Agraria, redactada según su autor en el invierno de 1795 a 1796, y publicada en 1797, responde a un hecho concreto que da lugar a una de las varias polémicas mantenidas por Paine con sus coetáneos conservadores. El hecho fue el escrito del obispo Watson, Una apología de la Biblia, criticando el libro de Paine titulado La Edad de la Razón. El obispo había titulado su escrito de la siguiente manera: "La sabiduría y bondad de Dios al haber creado ricos y pobres, con un apéndice que contiene reflexiones sobre el presente estado de Inglaterra y Francia". Paine, tras aducir que los clérigos debían dedicarse a solventar las miserias humanas y a hacer el bien, asegura que este escrito, contenido de un sermón del obispo, le decidió a publicar su libro, en el cual el principal argumento es la conversión paulatina de los pobres en ricos mediante un sistema redistributivo de los patrimonios cuando eran objeto de transmisión hereditaria, que veremos a continuación. ${ }^{27}$ Paine afirmaba que la pobreza no era un hecho natural, sino creado por la civilización, de la que pensaba que no había

los propietarios agrícolas -Quesnay, Dupont de Nemours, Lemercier de la Rivière. (Cfr. G. BABEUF, y otros, Realismo y utopía en la revolución francesa, Sarpe, Madrid, 1985, y QUESNAY, DUPONT DE NEMOURS, LEMERCIER DE LA RIVIËRE, L’ABBÉ BAUDEAU, LE TROSNE, Physiocrates, (ed. de E. DAIRE), Slatkine Reprints, Ginebra, 1971).

26 H.J. KAYE, Thomas Paine and the promise of America, Hill and Wang. Nueva York, 2006, p. 4.

27 Posteriormente, ya en el siglo siguiente, algunas propuestas siguieron el método de Paine para la redistribución de la riqueza mediante una renta agraria. Cornelius Blatchly defendía redistribuir la herencia entre las personas al alcanzar la mayoría de edad con razones próximas a Paine: la tierra era de todos y todos tenían derecho a una parte de la misma; el derecho de todos había sido injustamente expropiado; además toda la riqueza existente había sido obra del esfuerzo de generaciones históricas; Orestes Brownson afirmaba algo más, a lo que no se habían atrevido Paine y Blatchly: el derecho de propiedad se extinguía con la muerte del propietario, lo que justificaba que las propiedades se distribuyeran a las personas con vida. 
contribuido al bienestar de las generaciones, sino -todo lo contrario- había fomentado la extensión de la pobreza. ${ }^{28}$

En Paine encontramos ya, no únicamente la defensa y promoción, sino toda una organización de la RBU con su definición, titularidad, fundamentos y procedimientos.

\subsubsection{Definición}

La "renta del suelo", como dice el autor coincidiendo la expresión con lo que hoy denominamos RBU, es un derecho y no una muestra de caridad. La caridad nada alcanza, como tampoco la generosidad de los individuos y las minorías tratando de disminuir las miserias de los pobres. En su época los derechos sociales y las atenciones del Estado a los desfavorecidos brillaban por su ausencia. Por ello sorprende que en etapa tan temprana alguien considerara la renta del suelo como una renta para todos, que debería ser atendida y sufragada con un sistema estatal de redistribución de la propiedad mediante un impuesto a las transmisiones patrimoniales hereditarias. En esto consiste la renta del suelo: el derecho de todas las personas a una renta en dinero proporcionada por el Estado en una cantidad única de quince libras esterlinas al cumplir los 21 años y en cantidades anuales de diez libras desde que alcance los 50 años hasta su muerte, sin ningún tipo de condición. Se entiende que la renta se disfruta al comienzo de la vida laboral (21 años) y al final de la misma (50 años). Veamos los puntos del programa de redistribución de la riqueza del autor británico:

\subsubsection{Titularidad}

Concibe la RBU como un derecho de todas las personas, incluidas las mujeres y menores. No hay dudas al respecto, pues frecuentemente reitera que la RBU es un derecho que afecta a todos: "Se propone que los pagos, como se ha estipulado -dice Paine- se abonen a toda persona, ya sea rica o pobre" ${ }^{29}$ con lo que da a entender que la situación económica no es una va-

28 P. LINEBAUGH (Tomas Paine. Rights of Man and Common Sense, Verso, LondresNueva York, 2009, p. 31) aduce que el autor inglés llegó a la conclusión de que a más civilización correspondía mayor pobreza, y que contribuyó a esta idea la visión de la organización de los indios nativos de América, como los indios de Pensilvania, donde se estableció al llegar a América desde Inglaterra, a los que conoció de cerca.

29 R. SORIANO, E. BOCARDO, El sentido común y otros escritos, cit., p. 108.

DERECHOS Y LIBERTADES

Número 46, Época II, enero 2022, pp. 115-144
ISSN: 1133-0937

DOI: https://doi.org/10.20318/dyl.2022.6516 
riable para recibir o no los pagos de la renta del suelo. Incluso pone ejemplos concretos, como cuando sostiene que la renta de cada miembro de una pareja les ayudará a emprender un negocio para ganarse la vida. Esto es especialmente relevante, porque los pioneros de una RBU o de iniciativas afines suelen plantearla para destinatarios determinados y no para todo el colectivo de la sociedad.

\subsubsection{Fundamentos}

Paine hace una separación entre la común propiedad de la tierra y la propiedad privada. La primera es la que pertenece a todas las personas por el mero hecho de serlo. La segunda a quienes hayan producido mejoras en una tierra que en principio era de todos. "La tierra, en estado natural sin cultivar, -afirma- fue y debió haber continuado siendo LA PROPIEDAD COMÚN DE LA RAZA HUMANA (mayúsculas del autor)" ${ }^{30}$ Distingue entre estado natural y estado civilizado, entre tierra virgen y tierra cultivada. Todos los hombres en el estado natural eran propietarios de una parte alícuota de la tierra, pero posteriormente el sistema de propiedad personal de la tierra y el cultivo de la misma en el estado civilizado arrebataron la propiedad que era de todos y la convirtieron en la propiedad de unos pocos. El cultivo no es malo en sí mismo, sino en cuanto incorporado a la propiedad privada de la tierra, pues el cultivo según Paine ha sido uno de los más grandes adelantos de la invención humana, aunque haya desprovisto a muchos de su herencia natural y sin indemnización.

Pero, si la tierra era propiedad de todos primigeniamente y ahora nos la encontramos repartida y en propiedad de unos pocos, ¿qué hacer? Éste es el problema al que se enfrenta Paine y al que pretende dar solución; una solución que contente a todos los afectados por el conflicto y que él considera justa. "Mientras defiendo el derecho y me hago cargo de quienes fueron despojados de su herencia natural -dice- con la introducción de la propiedad de la tierra, defiendo igualmente el derecho del que posee la parte que es suya". ${ }^{31}$

Parte del respeto a la propiedad privada tal como está instalada en su época; en esto se diferencia claramente de los igualitaristas sociales, los partidarios de la igualdad económica y de la supresión de la propiedad privada, como Babeuf y sus correligionarios, más presentes en Francia que en las

\footnotetext{
$30 \quad$ Idem, p. 102.

31 Idem, p. 104.
} 
colonias inglesas. Entiende que los actuales propietarios no pueden ser despojados de las mejoras que sus antecesores han realizado sobre la tierra en principio virgen. La tierra virgen, cuando se convierte en tierra cultivada, es susceptible de propiedad. Y no pueden ser despojados porque la culpa no reside en ellos, sino en el sistema de apropiación de la tierra, que tiene sus orígenes en los tiempos remotos. Y así como sucesivas generaciones desde los orígenes fueron apropiándose de una tierra que no era suya, a partir de la introducción de su proyecto las sucesivas futuras generaciones irán restituyendo la propiedad de la tierra a todos los desposeídos. Como afirma Paine, "la culpa no es de los actuales propietarios. Ninguna queja se propone, y ninguna debe ser alegada en su contra, a menos que cometan el delito de oponerse a la justicia. La falta está en el sistema, y él ha robado imperceptiblemente al mundo, ayudado después por el derecho agrario de la espada". ${ }^{32}$

Recuerda Paine a su maestro Locke, cuando éste afirmaba que el trabajo era la justificación de la propiedad de la tierra, y que el límite de la propiedad residía en el techo del trabajo de una persona. Paine habla de cultivo y tierra cultivada que sólo puede acaecer mediante el trabajo.

Pero, al mismo tiempo, hay que restituir de alguna manera a las personas su herencia natural de la tierra que ha sido apropiada por otros, sin reformar el estado de cosas y violentar la actual distribución de la propiedad, sin cambiar los títulos vigentes de propiedad, y para ello el método más razonable y efectivo es la imposición de un diez por ciento a los patrimonios en el momento en el que son transmitidos por herencia a sus herederos. "Todo propietario de tierra cultivada -asegura- debe a la comunidad una renta del suelo (cursivas del autor), no sé de otro término mejor para expresar la idea del terreno que él posee; y es de esta renta del suelo de la que ha de surgir el fondo propuesto". ${ }^{33}$ De esta manera los actuales propietarios no son molestados en el disfrute de su propiedad y a los no propietarios se les restituye el derecho a la herencia de la tierra mediante la percepción de una cantidad de dinero extraída de la minoración de los patrimonios en las sucesivas transmisiones hereditarias.

\subsubsection{Procedimiento}

Paine se apoya para establecer los ítems de su muy detallado proyecto en los datos oficiales suministrados por el premier británico Mr. Pitt, que es-

$32 \quad$ Idem, p. 107.

33 Idem., p. 103. 
timaba la renta nacional de Inglaterra en trescientos millones de libras esterlinas (la cuarta parte de la renta de Francia y Bélgica). Según Paine en treinta años se produce una rotación total de los patrimonios, es decir, que son objeto de transmisiones hereditarias debido a las defunciones. Luego a un año corresponde la trigésima parte: 43.333 .333 libras esterlinas. De esta cantidad anual se detraería un diez por ciento aumentado en un diez por ciento más en el caso de las herencias que carecieran de herederos directos. Como la proporción entre los herederos directos y los indirectos es de 3 a 1, el resultado es de 30.000.000 libras esterlinas en el primer caso y 13.333.333. en el segundo. Y si a los herederos indirectos se les impone un diez por ciento complementario (añadido al diez por ciento inicial) se obtienen las cifras respectivas de 3.000.000 (herederos directos) y 2.666.666, que suman 5.666.666 libras esterlinas. Estas son las cifras de la restitución anual del total del patrimonio que rota anualmente mediante las transmisiones patrimoniales hereditarias.

Ahora queda por fijar las cifras de las personas que recibirían anualmente la renta del suelo. En esta distribución Paine sigue con suposiciones o conjeturas. De la población de Inglaterra de siete millones y medio de personas calcula que alcanzarían anualmente los veinte y un años 90.000 jóvenes y cincuenta años 400.000 adultos. Por lo tanto, los primeros arrojarían la cifra de 1.350.000 libras esterlinas a razón de 15 libras por persona y los segundos la cifra de 4.000.000 libras esterlinas a razón de 10 libras por persona. La cantidad final que emplearía el Estado para pagar anualmente la renta del suelo sería 5.350.000 libras esterlinas.

El plan de la distribución de la renta del suelo presentaría la siguiente organización:

1. En cada cantón el proceso sería encomendado a tres comisarios elegidos por las asambleas.

2. Los comisarios fijarán el valor de la propiedad transmitida y el diez por ciento correspondiente de su valor (herencias con herederos directos) o el veinte por ciento de su valor (herencias con herederos indirectos), exigiendo a los herederos la obligación de aportar al fondo la cantidad resultante. El título de la deuda será depositado en el Banco Nacional.

3. El heredero principal tendría la obligación de hacer los pagos en el plazo de un año desde la defunción con entregas trimestrales. El Banco Nacional emitiría pagarés contra las obligaciones de los herederos. 
Su proyecto basado en la renta del suelo está muy lejos de un proyecto caritativo o resultado de la generosidad de las instituciones o del Estado. Es diferente a otras iniciativas para la extinción de la pobreza por tres razones. Primero: es un plan que surge de la justicia y no de la caridad; no se da una limosna a nadie, sino que a todos se les concede el derecho que ya les pertenecía en los orígenes de los tiempos, cuando existía una real propiedad comunal de la tierra. "Es la justicia -y no la caridad- lo que constituye el principio del plan". ${ }^{34}$ Segundo, porque es un proyecto que se apoya en un derecho: el derecho a la renta del suelo de todas las personas de Inglaterra con la finalidad de paliar los efectos de la apropiación de una tierra común a todos y que las generaciones primeras se apropiaron injustamente. Tercero, es un proyecto estable y eficaz, pues trata de remediar la pobreza globalmente y para todos los tiempos, muy lejos de dispensar determinadas mejoras para aliviar la situación de las masas de indigentes. El plan propuesto -dice Paine- alcanzará a todos y evitará la presencia de pobres menesterosos.

El planteamiento teórico y metodológico de la renta del suelo de Paine presenta algunos problemas en mi opinión.

A) Quizás el más importante es la opción por el 10\% como porcentaje de la contribución de las herencias al fondo común, que sirve para la restitución a la comunidad del robo de la herencia común de la tierra. Señala Paine este porcentaje, como podría ser otro, teniendo en cuenta que a un mayor porcentaje de la contribución corresponde una mayor proximidad temporal para alcanzar la reparación completa. Pero claro es que el porcentaje elegido es una opción entre varias y que no se sabe cuándo se conseguirá la restitución total de la herencia usurpada. Son una ficción el porcentaje del 10\% y el momento histórico, en el que al fin se alcanzaría la deseada restitución y reparación del daño producido a la propiedad de toda la comunidad. El autor expresa que "sólo habría que sustraer de la propiedad una parte igual al valor de la herencia natural que ha sido absorbida". ${ }^{35}$ Es fácil decirlo, pero no tanto hacerlo y dar en el clavo. ¿Cuál es el porcentaje adecuado para que los propietarios no se llamen a la rebelión contra el sistema, ya que la principal preocupación de Paine es que su método no moleste a los propietarios y al mismo tiempo ayude a los menesterosos a salir de la pobreza?

${ }_{34} \quad$ Idem, p. 114.

35 Idem, p. 108. 
¿Hasta cuándo se mantendrá el fondo común y la imposición a las herencias para la devolución a la comunidad de la apropiación indebida de la tierra?

Paine piensa que este porcentaje del diez por ciento es una cifra razonable y estratégica; razonable para rescatar, año tras año, la propiedad de la tierra robada a la comunidad; estratégica para evitar el conflicto social, la lucha entre ricos y pobres, si el porcentaje se aplicara a los patrimonios en vida de sus propietarios.

B) Por las razones antes indicadas cabe decir lo mismo de las cifras de jóvenes y adultos que alcanzan, cada año, la edad de veinte y un y cincuenta años, respectivamente. Son cifras discutibles porque se apoyan en conjeturas.

C) Su plan tiene por objeto -reitera Paine en sus escritos- evitar los conflictos entre pobres y ricos, pero qué duda cabe de que los herederos se sentirían injustamente tratados con la merma de un diez o veinte por ciento de sus herencias. Podría importar menos quizás a los actuales propietarios, a los que en vida se les mantiene íntegra su propiedad, pero no a sus herederos. El plan no cumple, por lo tanto, con la finalidad que tanto pregona su autor, porque no evitaría el conflicto social.

D) Paine traza un plan de redistribución de la riqueza de largo futuro, que pretende que se vaya cumpliendo año tras año sin solución de continuidad, basado en unas cifras iniciales: los datos de la renta nacional y del padrón de población de Inglaterra de 1795 o $1796 .{ }^{36}$ Como la renta y la población de Inglaterra cambian a mayor con el paso de los años, sus datos y cifras, que se extienden nada menos que a treinta años venideros, no son fiables.

\section{MAXIMILIEN ROBESPIERRE}

Maximilien Robespierre ha sido interpretado de varias maneras; hoy se resucita su valor como líder revolucionario influyente y avanzado sin las acusaciones de otros tiempos, en los que se le consideraba como el más sanguinario de los revolucionarios, partidario del terror y la violencia para sos-

36 Son los años en los que dice Paine que redactó su Justicia Agraria al comenzar el prefacio de su obra, luego las cifras de renta y población que él maneja deben corresponder a uno de estos años. Publicó el libro un año después: 1797. 
tener a la república francesa. ${ }^{37}$ Ambos autores objeto de mi estudio corrieron la misma suerte: el olvido y desprecio de las generaciones que le sucedieron; por distintas razones: Paine por su crítica al cristianismo; Robespierre por su política del terror. Pocos publicistas se atrevieron a valorar su figura y aportaciones a la revolución. ${ }^{38}$ La visión negativa sobre el diputado de Arras procede no únicamente de la literatura sino de la opinión pública en general, que llega hasta nosotros. ${ }^{39}$

Sin embargo, Robespierre representa en tan diversos proyectos de la revolución la república profunda e igualitaria y la conquista de los derechos sociales. Son los temas que tratamos a continuación. Decía A. Mathiez, uno de sus mejores biógrafos, reivindicador ya en la primera mitad del siglo pasado de la obra de Robespierre, que si Rousseau fue el autor más avanzado en la teoría democrática, aquél lo fue en su llevanza a la práctica. ${ }^{40}$ Es uno de los más avanzados revolucionarios en contraste con sus correligionarios, defendiendo ya en el siglo XVIII los derechos sociales, como la universalización de la educación y lo que llamaba el derecho a la existencia (a la supervivencia o subsistencia, diríamos hoy). Es este derecho a la existencia el que nos permite hablar de Robespierre como uno de los pioneros de la renta básica universal. Fue también radical en su vida. Nos ha quedado la imagen de una persona de verbo rápido e hiriente; en sus discursos arremetía contra las nuevas instituciones, como la Asamblea Constituyente, igual que contra los poderosos y cínicos, que decían estar al lado de la revolución y la abandonaban cuando atentaba a sus intereses particulares. ${ }^{41}$

37 Una relación de las obras denigratorias y restauradoras del pensamiento y obra de Robespierre puede verse en Joan Tafalla, https://ddd.uab.cat/pub/reprep/18861970v2/ 18861970v2a15.pdf

38 M. MANFRED (Robespierre, Omegalfa, Biblioteca virtual, 2014, p. 30) alude a una excepción: “En vísperas de la tercera revolución - la revolución de 1848 - y de la Segunda República, Robespierre fue glorificado en los trabajos de Buchez y de Louis Blanc, muy diferentes por su carácter y su significación".

39 McPhee en su excelente monografía incorpora una encuesta de 1989, que en fecha tan cercana dedica a Robespierre los peores comentarios. También nos dice que "proyectaron sobre su figura acciones y motivaciones basadas en rumores" y destaca "los paralelismos ridículos entre su perfil y el de Mao Tse-Tung, Pol Pot e incluso Stalin o Hitler" (Cfr. P. MCPHEE, Robespierre. Una vida revolucionaria, Barcelona, Península, 2013, pp. 23.

40 "Los discursos de Robespierre -afirmaba- eran los principios del Contrato social en vía de realización, en lucha con las dificultades y los obstáculos, eran la teoría descendiendo del cielo a la tierra" (A. MATHIEZ, Etudes sur Robespierre, Editions Sociales, Paris, 1958, p. 23.

41 Las críticas a la Asamblea Constituyente son frecuentes en sus escritos. De ella decía: “Habría podido elevar al pueblo francés hasta el más alto grado de felicidad, de gloria y de li-

DERECHOS Y LIBERTADES

ISSN: 1133-0937

Número 46, Época II, enero 2022, pp. 115-144

DOI: https://doi.org/10.20318/dyl.2022.6516 
Robespierre es una figura equivalente a Jefferson en América septentrional. Ambos son los infatigables redactores de un sinfín de documentos de todo tipo en el proceso de las revoluciones liberales de las colonias británicas de América y de Francia. Jefferson en América, Robespierre en Francia. La diferencia personal entre ellos está en que Jefferson, de longeva vida, entraba y salía de la política, cobijándose de vez en cuando en su hacienda "Monticello" (por cierto con esclavos negros a su merced), mientras que Robespierre, de corta vida (muere a los 36 años), se dedicó completamente a la política. La diferencia ideológica es acusada. Jefferson se fija en las libertades individuales principalmente; el segundo en los derechos sociales preferentemente. Hay otra diferencia: Robespierre defiende la república francesa a ultranza, con toda clase de medios, también con la violencia. Jefferson no se sale de los procedimientos legales que va estableciendo la revolución.

\subsection{La libertad de la república. Virtud y Gobierno revolucionario en defensa de la república}

Se ha dicho que el diputado de Arras es un innovador de conceptos jurídicos y políticos. Sí, hasta cierto punto, pues en sus escritos es posible encontrar conceptos basados en aportaciones anteriores. Innovadora es la distinción entre Gobierno constitucional y Gobierno revolucionario. El primero conservador de la Constitución, que ya es una gran tarea ante enemigos interiores y exteriores. El segundo dinámico, cuyo fin es intentar innovar y alcanzar nuevas metas en la defensa de la república y la protección de los derechos de las personas necesitadas y la lucha contra la tiranía. Pero lo importante no es la definición de ambos tipos de Gobierno, sino las consecuencias de la calificación, pues así como el primero está sujeto a las propias normas constitucionales que defiende, el segundo debe estar libre de ellas, siendo justificado por la persecución del bienestar general en situaciones de amenaza y urgencia. Traza por lo tanto una peligrosa línea que distancia al Estado

bertad; y, por el contrario, ha permanecido muy por debajo de su sublime misión" (Exposición de mis principios, Articulo del primer número del diario Le Défenseur de la Constitución, mayo de 1792; véase en J. FUSTER, La revolución jacobina, Ediciones 62, Barcelona, 1992, p. 67) Y poco después, en un discurso ante la Asamblea Nacional, se expresaba con mayor dureza: “Si existe un espectáculo desagradable, éste es el que la Asamblea representativa sacrifique la seguridad de la Constitución a los intereses de algunos individuos ambiciosos y devorados por las pasiones" (Discurso pronunciado en la Asamblea Nacional el 21 de septiembre de 1791; J. FUSTER, La revolución jacobina, cit., p. 41). 
de Derecho, que en esas fechas se va construyendo por la revolución, y el Estado de Excepción, libre de reglas previas, que Robespierre justifica por la necesidad del éxito del Gobierno revolucionario. Estamos en un tramo del discurso en el que aparece un político justificando la violencia como arma política, lo que explica la mala percepción que sobre su figura ha tenido la posteridad.

El concepto de Robespierre de república es semejante al de Paine, desde el punto de vista de su razón de ser y de su estructura. En Paine la república es la única forma de gobierno buena (distanciándose de las aristotélicas) frente a la monarquía. Igualmente para Robespierre la única forma de gobierno es la república. En ambos se trata de una república representativa. Hasta aquí llegan las semejanzas, porque las diferencias son claras en los medios o instrumentos para alcanzarla. En el segundo encontramos toda una teoría del terror de Estado que no está presente en el primero

No es en cambio innovador Robespierre en la definición de la virtud como amor de los ciudadanos a la patria y a sus leyes y a la misma república, donde sigue una tradición que emana de los tiempos renacentistas. Es fácil hacer un parangón de Robespierre con Maquiavelo. Llama terror a la violencia en la esfera pública, un concepto hermanado con los de república, virtud y justicia. La defensa de la república a ultranza, asediada por enemigos internos y externos, a punto de perecer, justifica la práctica del terror. Éste es una consecuencia de la virtud, cuando ésta necesita de aquél para imponerse. Lo explica Robespierre con una de las frecuentes antítesis, que despliega en sus discursos: "La virtud, sin la cual el terror es cosa funesta. El terror, sin el cual la virtud es impotente" ${ }^{42}$ El terror es el medio, en definitiva, para hacer posible la virtud. También está relacionado con la justicia, porque ésta, como la virtud, lo necesita en el desarrollo de un Gobierno revolucionario. "El terror no es otra cosa -dice Robespierre- que la justicia expedita, severa, inflexible". ${ }^{43}$ Asume el concepto de virtud renacentista: el amor a la patria. No es, pues, original en su idea de virtud ciudadana como guía de la república. "La virtud -afirma- es, en sustancia, el amor a la patria y a sus leyes". ${ }^{44}$ La república es por su parte el bien supremo, la expresión de la más

42 Discurso pronunciado en la Convención Nacional, el 5 de febrero de 1794 (J. FUSTER, La revolución jacobina, cit., p. 147).

43 Ibídem.

44 Discurso pronunciado en el Club de los Jacobinos, 21 de junio de 1791 (J. FUSTER, La revolución jacobina, cit., p. 142). 
profunda democracia, por la que hay que luchar con los mayores sacrificios. Impresionante su posición en la Asamblea y la Convención, firme e inamovible, mientras que la gran mayoría de los diputados cambiaban de ideas y de bandos. Lo que le valió el apodo de "El Incorruptible". ${ }^{45}$ Unas palabras de su biógrafo, $\mathrm{H}$. Belloc, definen bien su carácter: "Cuando se consagraba a algo lo hacía con increíble tenacidad y llevaba en el espíritu una fortaleza inexpugnable donde guardaba inalterables sus convicciones". ${ }^{46}$

Las semejanzas con N. Maquiavelo son muy evidentes, hasta el punto que, salvando las circunstancias históricas, las frases de uno pueden ser trasladadas a los escritos del otro y viceversa. En Maquiavelo el mantenimiento de la república permite al gobernante el uso de medios ilícitos. ${ }^{47}$ La virtud es la cualidad de los ciudadanos protegiendo a la república de enemigos internos y externos; de los internos mediante el respeto a las leyes; de los externos por medio de una eficaz milicia. ${ }^{48} \mathrm{Y}$ la república es el mejor de los sistemas políticos que ha deparado la historia de los pueblos. ${ }^{49}$ Lo mismo cabe decir de D. Giannotti, autor florentino de la época de Maquiavelo, menos conocido que éste, que sigue las claves de la teoría jurídico-política renacentista. ${ }^{50}$

45 El apodo "El Incorruptible" no es posterior a la vida de Robespierre, sino una expresión con la que vulgarmente se le conocía en los ámbitos de la revolución, destacando su carácter y conducta como diputado de principios firmes e irrenunciables.

46 H. BELLOC, Robespierre, Editorial Juventud, Barcelona, 1985, pp. 29-30.

47 Escojo una de las muchas frases extraíbles del Príncipe o los Discursos: "En las deliberaciones en que está en juego la salvación de la patria, no se debe guardar ninguna consideración a lo justo e injusto, lo piadoso y lo cruel, lo laudable y lo vergonzoso, sino que, dejando de lado cualquier otro respeto, se ha de seguir aquel camino que salve la vida de la patria y mantenga su libertad" (N. MAQUIAVELO, Discursos sobre la primera década de Tito Livio, Alianza Editorial, Madrid, 2005, p. 433).

48 "Concluyo que no hay cosa más necesaria para la vida de una comunidad que... procurar que sean los ordenamientos y los hombres buenos" (N. MAQUIAVELO, Discursos sobre la primera década de Tito Livio, cit., p. 310).

49 "En la república es donde es posible la utilidad común que se deriva de la vida en libertad". "Lo que hace grandes a las ciudades no es el bien particular sino el bien común. Y sin duda este bien común no se logra más que en las repúblicas, porque éstas ponen en ejecución todo lo que se encamine a tal propósito" (N. MAQUIAVELO, Discursos sobre la primera década de Tito Livio, cit., pp. 82 y 196).

50 Para no ser reiterativa, prefiero no enunciar frases de Giannotti, que podrían ser pronunciadas tres siglos después por Robespierre. He dedicado un artículo a desentrañar los perfiles ideológicos de Giannotti y otro a establecer sus nexos y divergencias con Maquiavelo ("La república de Donato Giannotti: rara avis de la teoría política renacentista", Revista Internacional de Pensamiento Político, núm. 5, 2010, pp. 273-287; “De la república de Giannotti a la república de Maquiavelo", Revista Internacional de Pensamiento Político, núm. 4, 2009, pp. 181-193).

ISSN: 1133-0937

DOI: https://doi.org/10.20318/dyl.2022.6516
DERECHOS Y LIBERTADES

Número 46, Época II, enero 2022, pp. 115-144 
La defensa de la república, a toda costa, es una de las más relevantes exigencias de la virtud ciudadana. Y a Robespierre le cupo defender su idea de la república con el ejemplo. Por la conservación de la república, acechada por enemigos internos y externos, no dudó en pedir la muerte del rey en un vibrante discurso, porque únicamente su muerte podría garantizar la pervivencia de la república. O monarquía o república. Se había opuesto a la pena de muerte con una excepción: los casos en los que era necesaria su ejecución por motivos de seguridad nacional. Y ningún caso era más justificado y acuciante que la pena de muerte para Luis XVI, ya que su mera existencia era un enorme peligro para las conquistas de la revolución. "Luis debe morir -aseguraba- porque es necesario que la patria viva". ${ }^{51}$ Robespierre se extiende en todo tipo de argumentos en favor de su tesis: la muerte del rey sin previo proceso: argumentos filosófico, jurídico, político y estratégico. ${ }^{52}$ Interesa leer detenidamente el discurso, porque en él aparecen las razones de quienes preferían dejar al rey al margen de la revolución o, al menos, el pronunciamiento de una sentencia tras la celebración de un proceso; razones de todo tipo, que iban desde la defensa de la inmunidad de la persona del rey hasta el miedo a la venganza de las monarquías europeas.

La defensa de la república a ultranza llevó a Robespierre a construir una teoría del terror de altos vuelos (que hasta entonces no se había hecho), uniendo conceptos como virtud, gobierno revolucionario, libertad pública, justicia, república en torno al terror como instrumento de defensa de la república, cuya necesidad de implementación y ejecución dependía de la fortaleza o declive de la propia república. La etapa de los últimos años de la república, en las postrimerías de la Convención, se caracterizó por una reglamentación jurídica del terror como arma salvífica según el diputado de Arras para conservar la república. ${ }^{53}$ Es curioso contrastar, por otra parte, cómo el

51 Discurso pronunciado en la Convención Nacional, el 3 de diciembre de 1792 (A. MARTÍNEZ ARANCÓN, La Revolución francesa en sus textos, Tecnos, Madrid, 1989, p. 85).

52 Merece la pena reseñar someramente los argumentos: a) filosófico: la contradicción lógica entre república y monarquía: la república no existe si en ella convive un rey; o una u otro; b) jurídico: al caso hay que aplicar el derecho de gentes y no el derecho positivo nacional; además el rey está fuera de la república, sus leyes y lo derechos de los ciudadanos; estos derechos únicamente pueden sobrevivir si el rey no existe; c) político: la pena de muerte se justifica porque lo exige la seguridad nacional, que está por encima de los derechos de los ciudadanos; d) estratégico: cuanto más se tarde en aplicar la pena de muerte al rey, de más tiempo disfrutarán las monarquías extranjeras para restaurarle en el trono.

53 C. Aguilar, que ha estudiado el terror del Estados en varios épocas y regímenes políticos, apunta la "legalización del terror" como obra de Robespierre y correligionarios, que 
terror es necesario para el triunfo de la revolución y la guerra por el contrario es contrarrevolucionaria. La guerra puede distraer de la consumación de la revolución y poner en peligro a la república al concitar contra ella el concierto de las potencias extranjeras. ${ }^{54}$

\subsection{Los derechos sociales y la universalización del derecho a la existencia}

No solo en el tema de los derechos civiles y políticos, sino en el de los derechos sociales Robespierre avanza y profundiza. En su enunciado y fundamentación de los derechos sociales se sitúa claramente en la izquierda de la revolución, señalando una serie de derechos sociales -la educación, la exención de tributos de los pobres, la progresión de los impuestos en función del patrimonio, la subsistencia, etc.- que son derechos nuevos para una época, en la que la cuestión primordial era la consecución de los derechos civiles y políticos. En el discurso quizás más importante y citado del autor pronunciado el 24 de abril de 1793 se encuentra una lista de nuevos derechos sociales que posteriormente formarían parte de la Constitución de 1793. Son un conjunto de derechos que conforman lo que en el texto se denomina una declaración de derechos. Los derechos son ya presentados con una enumeración. El artículo 14 formula la universalidad de la educación: "la sociedad debe favorecer con todo su poder los progresos de la razón pública, y hacer la instrucción accesible a todos los ciudadanos". El artículo 11 enuncia el deber de la sociedad de garantizar la existencia de todas las personas: "la sociedad está obligada a procurar la subsistencia de todos sus miembros, ya sea proporcionándoles trabajo, ya asegurando los medios de existencia a quienes están incapacitados para trabajar". Esta subsistencia sería asegurada por dos medios alternativos: la encomienda de un trabajo o en su defecto la ayuda del Estado.

El derecho-deber de existencia se complementa con la exención de tributos de los pobres, que a su vez se correlaciona con el deber de subvenir a

sirvió de precedente para experiencias similares del futuro, (Véase C. AGUILAR, “El Terror de Estado francés: una perspectiva jurídica”, Revista Internacional de Pensamiento Político, núm. 7, 2012. pp. 207-243.

54 Uno de los mejores conocedores de Robespierre, S. Zizek, en la presentación de su monografía sobre Robespierre asegura: "Para Robespierre, el terror revolucionario es lo más opuesto a la guerra...era muy consciente de que la guerra entre las naciones sirve por lo general como medio para ofuscar la lucha revolucionaria dentro de cada país." (S. ZIZEK Slavoj Zizek presenta a Robespierre. Virtud y Terror, Akal, Madrid, 2010, p. 8). 
las necesidades sociales de los pudientes mediante un sistema de impuestos estatales progresivos: quien más tiene, más debe contribuir. Así lo expresa el artículo 13: "los ciudadanos, cuyos ingresos no exceden a lo necesario para su subsistencia, están eximidos de contribuir a los gastos públicos. Los demás deberán soportarlos progresivamente, según la importancia de su fortuna". Robespierre establecía un parangón entre la garantía de la existencia de las personas y los tributos progresivos al Estado, porque serían éstos los que podrían contribuir a subvenir las necesidades de los pobres desprovistos de trabajo. Si no hay trabajo, ahí está el Estado para atender a los menesterosos. ${ }^{55}$

El discurso citado se complementa con otro anterior, de 2 de diciembre de 1792, pronunciado en la Convención, donde Robespierre habla del derecho a la existencia como el primer derecho y "la primera ley social es la que garantiza a todos los miembros de la sociedad los medios para existir" Este texto entrecomillado es el encabezamiento de su discurso. Entresaco el párrafo extenso y más importante del discurso en consonancia con el encabezamiento: “¿Cuál es el primer objetivo de la sociedad? Es mantener los derechos imprescriptibles del hombre. ¿Cuál es el primero de estos derechos? El derecho a la existencia. La primera ley social es pues la que garantiza a todos los miembros de la sociedad los medios de existir. Todos los demás están subordinados a éste. La propiedad no ha sido instituida o garantizada para otra cosa que para cimentarlo. Se tienen propiedades, en primer lugar, para vivir. No es cierto que la propiedad pueda oponerse jamás a la subsistencia de los hombres. Los alimentos necesarios para el hombre son tan sagrados como la propia vida. Todo cuanto resulte indispensable para conservarla es propiedad común de la sociedad entera; tan sólo el excedente puede ser propiedad individual, y puede ser abandonado a la industria de los comerciantes. Toda especulación mercantil que hago a expensas de la vida de mi semejante no es tráfico, es bandidaje y fratricidio". ${ }^{56}$

55 Véanse los artículos citados de la Declaración en el discurso pronunciado en la Convención Nacional el 24 de abril de 1793, vulgarmente conocido como el "discurso sobre la propiedad", pero que presenta un título más extenso: Sobre la propiedad. Seguido del proyecto de Declaración de los Derechos del Hombre y del Ciudadano. Se trata de un amplio discurso, que abarca mucho más que las ideas de su autor sobre la propiedad, y de extraordinaria importancia histórica, porque algunos de los artículos fueron directamente vertidos en la Constitución de 1793 (J. FUSTER, La revolución jacobina, cit., pp. 106-110).

56 Véase Maximilien Robespierre. Por la Felicidad y por la Libertad. Discursos, selección y presentación de YANNICK BOSC, FLORENCE GAUTHIER Y SOPHIE WAHNICH, Ediciones de Intervención Cultural/El Viejo Topo, Madrid, pp. 154-164, donde las cuidadoras de la edición afirman al final de la presentación: "Estamos ante el nacimiento de una concep- 


\subsection{La indistinción entre derechos políticos y derechos sociales: el reconocimiento de ambos tipos de derechos en el mismo plano de la relevancia jurídica}

Es muy importante el enunciado de este epígrafe, que coloca a los derechos políticos y a los derechos sociales en el mismo lugar del reconocimiento y la aplicación. Importante porque se separa Robespierre de sus correligionarios para quienes la conquista de los derechos políticos y las libertades era el techo a conseguir, que es lo que realmente ha quedado en el constitucionalismo de la época; es necesario aguardar al siglo siguiente para encontrar el reconocimiento jurídico de algunos derechos sociales. Pero también es relevante, porque en el número de los derechos sociales se incluye al derecho a la existencia, con lo que este derecho alcanza el máximo posible de relevancia jurídica. Robespierre se sitúa así al margen del proceso de conquistas sucesivas de las generaciones de los derechos humanos; primero, las libertades; después, los derechos sociales. Podemos entresacar muchas citas de sus discursos para corroborar este aserto. Pero mejor es ir a su Declaración de los Derechos del Hombre y del Ciudadano, formulada con articulado en uno de sus discursos de referencia; en ella expresa en el artículo 1 que "el objeto de cualquier asociación política es la conservación de los derechos naturales imprescriptibles del hombre y el desarrollo de sus facultades". Y, ¿cuáles son esos derechos imprescriptibles? Va enunciándolos uno a uno en un amplio texto articulado y al principio, ya en el artículo 2, refiere los principales derechos, que son la libertad y la existencia: "Los principales derechos del hombre son los de subvenir a la conservación de su existencia y la libertad". No pone a uno tras otro, sino ambos -libertad y existencia- en el mismo plano de relevancia jurídica

\subsection{El derecho-deber de existencia y la renta básica universal}

En primer lugar, el derecho a la existencia es lo mismo que el derecho a la subsistencia. Existencia equivale a subsistencia o vida. Así se despren-

ción de la economía política que se puede calificar de socialista, en la que el derecho social viene a limitar al derecho privado para asegurar el derecho a la existencia de cada uno, que es el fin de la sociedad" Es interesante esta colección de los discursos de Robespierre, porque es bastante completa y complementa otras existentes, donde no se contienen todos sus discursos. Publicada anteriormente como Maximilien Robespierre, Pour le bonheur et pour la liberté, La fabrique editions, Paris, 2000.

http://www.elsarbresdefahrenheit.net/documentos/obras/2176/ficheros/127222226_Maximilien_ Robespierre_Por_La_Felicidad_y_Por_La_Libertad_Discursos.pdf 
de de los textos del autor. La existencia no es una cuestión filosófica para Robespierre, dicho más explícitamente. Es una cuestión física. Existencia como posibilidad de subsistir y vivir. Me ha llamado la atención las diversas interpretaciones de la doctrina sobre cómo enfrenta Robespierre lo que él denomina la existencia. Unos hablan de la obligación de la sociedad de garantizar la existencia de las personas y otros del derecho a la existencia. O el deber de la sociedad y el Estado o el derecho de las personas. Pero en realidad el autor que nos ocupa une ambas cosas: el deber y el derecho. Y lo hace reiteradamente. Y para que no haya lugar a dudas en la ya referida Declaración de los Derechos del Hombre y del Ciudadano dedica sendos artículos a recoger estas dos dimensiones jurídicas de la existencia de las personas. En efecto, en el artículo 2 cita al "derecho a la conservación de la existencia" como uno de los dos principales derechos y en el artículo 11 señala que "la sociedad está obligada a garantizar la subsistencia de todos sus miembros". Por lo tanto, nos encontramos, como dice el enunciado del epígrafe, ante un derecho-deber de existencia; derecho para las personas y deber para la sociedad y la organización que ésta se ha dado, el Estado.

Los partidarios de la RBU siempre colocan a Robespierre entre los pioneros de ésta. Considero que es admisible, porque con su propuesta todas las personas quedaban cubiertas en sus necesidades básicas, bien por el trabajo o por la subvención del Estado, en el caso de que no trabajaran. Pero es un planteamiento de la RBU distinto al concepto tal como hoy la entendemos: la contribución del Estado dirigida a todas las personas por el mero hecho de serlo, trabajen o no. Si comparamos a Robespierre con Paine, la actitud de éste es más clara y apropiada en su papel de pionero o precursor de la RBU, como ya hemos podido comprobar.

\section{CONCLUSIONES: LOQUE UNE Y SEPARA A PAINE Y ROBESPIERRE}

Podríamos definir a Paine y Robespierre como revolucionarios radicales republicanos. Son dos activistas revolucionarios, que les cupo la suerte de vivir de lleno y en primera fila la revolución contra la monarquía absoluta dominante en Inglaterra y Francia con el gaje de pasar el primero sus últimos años pobre y solitario y el segundo terminar ejecutado en la guillotina, ambos despreciados y vilipendiados en siglos posteriores. Son auténticos revolucionarios, porque contribuyeron con sus acciones y escritos al triunfo de las revoluciones liberales, que dieron paso a una nueva concepción del 
Estado (los nacientes Estados liberales de América septentrional y el Estado liberal francés). Son radicales porque ambos promueven en el espectro ideológico de la época las reformas políticas más extremas. Paine contrasta con las posiciones más moderadas de los revisionistas, los federalistas y liberales moderados del nuevo mundo. Robespierre se separa de las posiciones moderadas de los fisiócratas y liberales franceses, que formaban el núcleo de los opositores al absolutismo, y se aproxima a los igualitaristas sociales. Finalmente profesan un intenso republicanismo, un republicanismo de idea y vida, pues ambos lucharon con riesgo para sus propias vidas para destruir los cimientos de las monarquías absolutas dominantes en Europa y construir desde sus cenizas una nueva república presidida por los principios racionales que hoy conforman lo que denominamos liberalismo político y Estado de Derecho.

Les une la semejanza en la defensa de la república contra la monarquía, aunque en distintos contextos históricos, políticos y sociales. El diseño de la república en ambos es el de una república representativa que reúne las características propias del naciente liberalismo político en América septentrional y Francia: la soberanía del pueblo, el pacto social para acordar una forma de gobierno, elecciones de los representantes y gobernantes, imperio de la Constitución y la ley como fuente del derecho. Hay, no obstante, dos importantes diferencias. La primera es la construcción en dos etapas de la república en Paine, porque era necesario en primer lugar la independencia de las colonias inglesas respecto a la monarquía absoluta de Inglaterra y después la formación de la república. El paso previo a la república era la segregación territorial y política que no fue necesaria en Francia, donde la nueva república surge en el mismo territorio.

La otra diferencia es la defensa y el uso de la violencia interna por parte de Robespierre, ausente en Paine. No es que éste segundo estuviera al margen de la violencia, pero era ésta una violencia externa contra el enemigo opresor, Inglaterra. La defendida por Robespierre se producía entre los compatriotas franceses como el único recurso según él para mantener la república. El terror se convertía en virtud como instrumento necesario para una república que perseguía la libertad y el bienestar de los ciudadanos franceses. En Paine la violencia está fuera en forma de guerra, En Robespierre está dentro en forma de necesario recurso republicano. En este contexto la opinión sobre la guerra de ambos es diametralmente opuesta: la guerra es el único medio para el triunfo de la república según Paine; sin embargo, Robespierre 
rechaza en sus discursos frontalmente la guerra contra las potencias extranjeras, porque sería contrarrevolucionaria, "una revolución sin revolución", y pondría en peligro la conservación de la república.

Pasando ahora al ámbito de los derechos sociales separa a ambos la posición sobre una renta básica universal (fijándonos en sus expresiones: la "renta del suelo" de Paine y el "derecho a la existencia" de Robespierre). A pesar de que en cierta literatura jurídica a ambos se les pone en el mismo lugar como pioneros, antecesores o precursores de esta renta. Paine es un precursor de una renta básica universal, explicada con todo tipo de detalles en su Justicia Agraria, libro dedicado exclusivamente a su fundamentación y diseño. A Robespierre, en cambio, le viene bien el título de defensor del derecho de subsistencia condicionada, porque realmente no defiende lo que hoy llamamos renta básica universal, de la que es titular la persona por el mero hecho de serlo, sin necesidad del acompañamiento de ciertas circunstancias o condiciones, sino una renta para quienes están en la pobreza y carecen de trabajo. Precisamente hay dos partidos políticos españoles, el PSOE y Podemos, que en las elecciones generales de 2016 incorporaron en sus programas una figura semejante a la propuesta de Robespierre: el ingreso mínimo vital del primero y la renta complementaria garantizada del segundo. Podemos sí que llevó en su programa a las elecciones europeas de 2014 una renta básica universal, que posteriormente abandonó. El único caso en el que ha aparecido en los programas electorales de los partidos políticos con representación parlamentaria hasta ahora.

María Luisa Soriano GonZÁlez Universidad Pablo de Olavide Carretera de Utrera, Km. 1 Sevilla 41013 e-mail:mlsorgon@upo.es 